\title{
VERY EARLY CHILDHOOD SCHIZOPHRENIA: A CASE REPORT
}

\section{D.D. SANTOS SILVA1, D. NOBRE BARBOSA2, G. VASCONCELLLOS AMARAL3.}

1 Universidade Federal do Rio de Janeiro, Instituto de Psiquiatria, Rio de Janeiro, Brazil.

2Unidade Local de Saúde do Litoral Alentejano, Unidade Local de Saude do Litoral Alentejano, Santiago do Cacém, Portugal.

3Fundação André Arcoverde, Faculdade de Medicina de Valença, Valença, Brazil.

\section{BACKGROUND}

Childhood-onset schizophrenia is a severe form of psychotic disorder that occurs at age 12 years or younger and is often chronic and persistently debilitating, with worse outcomes than patients who have later onset of symptoms. The definition of childhood schizophrenia has evolved over time and is now believed to be a virulent childhood version of the same disorder exhibited in adolescents and adults. The differentiation and significance of "childhood-onset," versus "early onset," versus "adult onset" is being explored, especially as it pertains to its utility to determine prognosis. The American Psychiatric Association's Diagnostic and Statistical Manual of Mental Disorders, Fifth Edition (DSM-5) cautions that although the essential features of schizophrenia are the same in childhood, it is harder to diagnose. Symptoms such as disorganized speech and behavior, which are typically present in schizophrenia, also occur in many disorders of childhood onset (e.g., autism spectrum disorder, obsessive compulsive disorder, and attention-deficit hyperactivity disorder).

\section{OBJECTIVES}

The present study seeks to show a case of very early childhood schizophrenia in a psychosocial care center and its approach.

\section{MATERIALS AND METHODS}

This study is a case report.

\section{CASE REPORT}

D.P.S., 09 years old, male, elementary school. Arrives at the Center for Psychosocial Care sent by a neurologist. At the initial examination, the patient was very disorganized and indifferent, with monosyllabic speech that did not correspond to the attempt to communicate. Father says that the symptoms started suddenly six months ago, with disorganized thinking, insomnia and restlessness, without improvement since then, all the non-psychiatric possibilities for the picture have been discarded. Aripiprazole $10 \mathrm{mg} /$ day was started, with progression to $15 \mathrm{mg} /$ day. In addition to the drug regimen, it was also included in therapeutic group workshops, such as music therapy and art therapy. Despite the drug treatment and the attempt to organize with playful therapeutic methods, it is observed the maintenance of the severe psychotic picture with predominance of the negative symptoms and the disorganization of the thought, characteristic of the disease started in this age group. The family has had psychological support and guidance about the disease, ways to cope and care for the sick person.

\section{RESULTS AND CONCLUSIONS}

The appearance of symptoms of psychosis before age 12 is rare (less than one-sixtieth as common as the adult-onset type), but studying these cases is important for understanding this disorder. For those who might develop psychotic disorders or schizophrenia as adults (adult-onset), it is not uncommon for them to start experiencing early warning signs during puberty or adolescence. The period of time when an adolescent experiences the early warning signs of psychosis is called prodrome. During this time, youth recognize that their experiences (hearing or seeing things that are not there) are strange or concerning. Being aware of the early warning signs and offering support is crucial. Most children with schizophrenia show delays in language and other functions long before their psychotic symptoms (hallucinations, delusions, and disordered thinking) appear. In the first years of life, about $30 \%$ of these children have transient symptoms of pervasive developmental disorder, such as rocking, posturing, and arm flapping. Childhood-onset of psychosis may present with poor motor development, such as unusual crawling, and children may be more anxious and disruptive compared to those with later onset. It is especially important to pay attention to sudden changes in thoughts and behaviors. Keep in mind that the onset of several of the symptoms below, and not just any one change, indicates a problem that should be assessed. The symptoms below should not be due to recent substance use or another medical condition.

\section{REFERENCES}

Aneja J, Singhai K, Paul K. Very early-onset psychosis/schizophrenia: Case studies of spectrum of presentation and management issues. J Family Med Prim Care. 2018;7(6):1566-1570.

Pantano $\mathrm{T}$ et al. Thought and language disorders in very early onset schizophrenia, schizoaffective disorder and bipolar disorder. Arch Clin Psychiatry. 2016;43(4):67-73 